IUS ET SCIENTIA (ISSN 2444-8478) 2018, Vol 4 nº 2, pp.63-86

"El fenotipado forense", Susana ÁLVAREZ DE NEYRA KAPPLER, Universidad Autónoma de Madrid, susana.alvarezdeneyra@uam.es

Recibido: 30/10/2018. Aceptado: 01/12/2018

DOI: http://dx.doi.org/10.12795/IESTSCIENTIA.2018.i02.05

\title{
EL FENOTIPADO FORENSE
}

\section{THE FORENSIC DNA PHENOTYPING}

\author{
Prof ${ }^{a}$ Dra. Susana ÁLVAREZ DE NEYRA KAPPLER
}

\section{RESUMEN}

Las regiones utilizadas en identificación genética son las no sensibles o no codificantes; es decir, aquellas que no proporcionan información sensible del individuo. Así lo establece expresamente el art. 4 de la LO 10/2007, reguladora de las bases de datos policiales, que circunscribe la identificación genética a la utilización de este ADN llamado $<<$ basura $>>$. Las regiones no codificantes, si bien unidas funcionan como un código de barras de una persona, por sí solas no ofrecen información de cómo es o de cómo se comporta el individuo. Pero el ADN de esas muestras también cuenta con otras regiones codificantes, llenas de información. Y es ahí donde la genética forense tiene su mayor campo de extensión; la <<última revolución〉> de los laboratorios forenses: el fenotipado forense. Básicamente, lo que pretende esta técnica es predecir el aspecto humano a partir de una muestra de ADN hallada en la escena del delito a fines de investigación criminal. La ciencia ha avanzado lo suficiente como para que los forenses puedan elaborar un retrato robot aproximado de una persona a partir de una pequeña muestra de ADN.

\section{PALABRAS CLAVE}

Proceso penal, prueba, fenotipado forense, testigo, ADN.

\begin{abstract}
The regions used in genetic identification are non-sensitive or non-encoding; that is to say, those that do not provide sensitive information of the individual. This is expressly stated in article 4 of the LO 10/2007, which regulates the Police Databases, which circumscribes the genetic identification to the use of this DNA called junk. Non-coding regions, while united, function as a bar code for a person, but they do not provide information on how the individual is or how it behaves. But the DNA in those samples also has other coding regions, full of information. And that's where forensic genetics has
\end{abstract}


IUS ET SCIENTIA (ISSN 2444-8478) 2018, Vol 4 nº 2, pp.63-86

"El fenotipado forense", Susana ÁLVAREZ DE NEYRA KAPPLER, Universidad Autónoma de Madrid, susana.alvarezdeneyra@uam.es

Recibido: 30/10/2018. Aceptado: 01/12/2018

DOI: http://dx.doi.org/10.12795/IESTSCIENTIA.2018.i02.05

its largest field of extension; the last revolution of the forensic laboratories: the Forensic DNA Phenotyping.

Basically, the aim of this technique is to predict the human aspect from a DNA sample found at the scene of the crime for the purpose of criminal investigation. Science has advanced long enough for forensics to draw up an approximate robot portrait of a person from a small DNA sample.

\section{KEYWORDS}

Criminal prosecution, evidence, forensic phenotyping, witness, DNA.

"Las técnicas de organización e investigación son los sustituidos que han de erradicar las prácticas viciosas, heredadas del sistema basado en la tortura y la confesión que, aún prohibido desde hace más de un siglo y medio, no dejará de vivir subterráneamente, en tanto no sea suplantado con ventaja por métodos acordes con el respeto a los derechos fundamentales".

VIVES ANTÓN

\section{INTRODUCCIÓN}

Qué duda cabe que en todo proceso penal se busca hallar la verdad formalizada de los hechos. Determinar la existencia del delito y su posible autoría, respetando las reglas del Estado de derecho, es fundamental para satisfacer la necesidad social de la persecución del infractor.

Los avances de la ciencia han contribuido a la consecución de este fin. No obstante, no se debe abandonar en ningún caso la perspectiva de entender las nuevas 
IUS ET SCIENTIA (ISSN 2444-8478) 2018, Vol 4 nº 2, pp.63-86

"El fenotipado forense", Susana ÁLVAREZ DE NEYRA KAPPLER, Universidad Autónoma de Madrid, susana.alvarezdeneyra@uam.es

Recibido: 30/10/2018. Aceptado: 01/12/2018

DOI: http://dx.doi.org/10.12795/IESTSCIENTIA.2018.i02.05

pericias para la determinación del imputado como una manera de realizar la imprescindible actividad de investigación de unos hechos, presuntamente delictivos, sin vulnerar los derechos fundamentales de los sujetos afectados. Ello frente a la clásica forma de obtener confesiones mediante malos tratos o torturas, proscritas en un Estado de derecho. La utilización de las modernas pericias no solo tiene el beneficio de que supongan una menor vulneración de derechos, sino que también son, en la medida en que tienen una base científica, mucho más acordes con la verdad real.

Como bien es sabido, la determinación del investigado es presupuesto necesario para la apertura del juicio oral y su acusación. Constituye un elemento esencial de la fase de instrucción, pues sin identificar a aquél, la finalidad del proceso se vuelve imposible al no poder imponérsele, en caso de merecerlo, una sanción por el delito cometido.

La idea de la determinación del imputado como un objetivo fundamental de la instrucción la recoge el artículo 299 de la Ley de Enjuiciamiento Criminal, actuación que consiste en la concreción de la persona que presuntamente cometió los hechos, para diferenciarla de las demás ${ }^{1}$.

Para lograr la identificación del presunto autor del delito, resulta imprescindible articular otros mecanismos más allá de la clásica Regina probatorum de la prueba testifical. A lo largo del tiempo, la historia nos muestra los adelantos de la técnica y de la ciencia en la identificación de los presuntos responsables de los hechos. Probablemente, a los efectos apuntados, el estudio y análisis del ácido desoxirribonucleico (ADN), como contenedor de la huella genética de organismos vivos, ha sido uno de los descubrimientos más revolucionarios en los últimos tiempos, y es que, como las huellas dactilares, cada individuo tiene su propia secuencia única de $\mathrm{ADN}^{2}$, lo que le hace distinto de todos los demás. Fue en 1953 cuando dos científicos, WATSON y CRICK, consiguieron descifrar la estructura del ADN, si bien la resolución

\footnotetext{
${ }^{1}$ La Ley de Enjuiciamiento Criminal sólo hacía referencia al "reconocimiento en rueda", quizás porque al momento de su promulgación, en 1882, era la única diligencia de determinación admitida y de fácil realización. Sin embargo, el desarrollo científico que ha tenido lugar tras su promulgación, permite que a día de hoy se puedan emplear muchas otras.

${ }^{2}$ El ADN o ácido desoxirribonucleico es una molécula compleja que contiene toda la información necesaria para construir y mantener un organismo. Esta información es heredada de padres a hijos. La información genética está presente en casi todas las células del cuerpo y caracteriza a los individuos de forma única.
} 
IUS ET SCIENTIA (ISSN 2444-8478) 2018, Vol 4 nº 2, pp.63-86

"El fenotipado forense", Susana ÁLVAREZ DE NEYRA KAPPLER, Universidad Autónoma de Madrid, susana.alvarezdeneyra@uam.es

Recibido: 30/10/2018. Aceptado: 01/12/2018

DOI: http://dx.doi.org/10.12795/IESTSCIENTIA.2018.i02.05

de casos judiciales con la ayuda del ADN no se produjo hasta 1985, gracias a los avances en esta materia desarrollados por JEFFREYS, profesor de Genética de la Universidad de Leicester, y su equipo.

La huella genética se ha convertido en una de las herramientas más precisas para la identificación de los individuos. Tiene múltiples aplicaciones, no solo en la investigación científico-técnica de los delitos, o en la identificación de restos humanos y de personas desaparecidas; también en pruebas de paternidad y en la medicina.

Como hemos apuntado, en investigación criminal los análisis genéticos se utilizan desde hace más de dos décadas y han revolucionado las investigaciones forenses, hasta el punto de ser considerados a día de hoy la $<<$ prueba estrella $>>$ del proceso penal. Dado que los seres humanos dejan un rastro de $\mathrm{ADN}$ a donde quiera que vayan, los investigadores forenses aprovechan este hecho para obtener información; utilizan el ADN como prueba para evaluar las probabilidades de observar el material biológico, dadas algunas diferentes hipótesis.

Los cotejos de ADN han servido tanto para incriminar a los autores de los delitos, como para absolver a personas que fueron encarceladas por error cuando la genética aún estaba dando sus primeros pasos, comparando dos muestras de ADN para buscar la coincidencia -o no- de perfiles genéticos. Sin embargo, no es una técnica infalible y su resultado no ofrece la certeza, sino un resultado matemático de posibilidad o probabilidad de coincidencia ${ }^{3}$.

En la actualidad se están desarrollando en Estados Unidos y en Europa, métodos de estudio acerca del ADN, que permiten identificar las características físicas e incluso biogeográficas del ser humano, partiendo de una pequeña muestra de su material biológico: pelo, sangre, sudor, saliva, semen...

\footnotetext{
${ }^{3}$ Antonio ALONSO ALONSO apunta a lo que él define "el efecto CSI". "El uso del ADN en la investigación criminal o en la identificación de personas desaparecidas, ha sido objeto de un gran número de series cinematográficas de gran audiencia que crean expectativas poco realistas sobre las posibilidades de estas pruebas. En este sentido, los especialistas forenses hablan ya del efecto CSI (Crime Scene Investigation): la concepción de que la ciencia forense es infalible e inmediata, lo que puede generar una visión distorsionada de la prueba en jueces, fiscales y, especialmente, jurados de los tribunales de justicia. La parte positiva del efecto CSI tiene que ver con el creciente interés de los jóvenes por los temas forenses y el incremento exponencial en el número matriculados en este tipo de cursos de especialización". ADN forense, investigación criminal y búsqueda de desaparecidos. DOI: http://dx.doi.org/10.18567/sebbmdiv_RPC.2011.12.1. Artículo publicado en diciembre de 2011.
} 
IUS ET SCIENTIA (ISSN 2444-8478) 2018, Vol 4 nº 2, pp.63-86

"El fenotipado forense", Susana ÁLVAREZ DE NEYRA KAPPLER, Universidad Autónoma de Madrid, susana.alvarezdeneyra@uam.es

Recibido: 30/10/2018. Aceptado: 01/12/2018

DOI: http://dx.doi.org/10.12795/IESTSCIENTIA.2018.i02.05

Según un artículo publicado en PLoS $\mathrm{ONE}^{4}$, un equipo dirigido por Peter CLAES $^{5}$, de la Universidad de Leuven (Bélgica), elaboró un trabajo en el que se relacionaban los genes con los rasgos faciales de un grupo de voluntarios ${ }^{6}$.El equipo ha desarrollado la forma de plasmar el rostro de una persona a partir de una muestra de ADN que, correctamente codificada y procesada, y a su vez, ayudada de un programa informático, puede dar algo muy parecido a un retrato robot. Se trata de un experimento que nos permite descubrir las relaciones entre la variación facial y los efectos del sexo, ascendencia genómica y un subconjunto de genes craneofaciales, que puede resultar de gran ayuda cuando para concretar qué perfil biogeográfico estamos buscando, con una serie de características básicas.

Estas nuevas técnicas, aún en desarrollo, reciben el nombre de "fenotipado molecular" y van más allá de los principios del ADN como sistema identificador de altísima fiabilidad. El fenotipado o retrato molecular entra en el campo del análisis de determinados genes que configuran, entre otras cosas, nuestro aspecto físico ${ }^{7}$. Un

\footnotetext{
${ }^{4}$ Sección PLoSGenetics.

${ }^{5}$ CLAES, P. Proyecto Facial recognition from DNA predictable traits. Vid.,asimismo, del mismoautor, Manifold Data Analysis with Applications to High-Frequency 3D Imaging. La base de la investigación de CLAES se centra en la visión del ordenador y en el análisis de imágenes médicas con extensiones obtenidas y probadas en bioestadística, genética, biología humana y enfermedades, así como en psicología cognitiva.

${ }^{6}$ En total 592 voluntarios: 154 de los EE.UU., 191 de Brasil, y 247 desde Cabo Verde. Además, la edad de los participantes que componía la muestra era de entre 18 y 40 años para poder minimizar la variación de la morfología facial. Se tomaron diferentes imágenes en 3D desde distintas perspectivas de la cara lo que redundó en 7.000 puntos de referencia de la misma. Se centraron en 24 mutaciones de 20 genes, lo que dio algo parecido a un retrato robot. Con todo ello, se obtuvo un algoritmo informático capaz de recrear el rostro de una persona, en una imagen en 3D, a partir de su ADN. Algunos de los rasgos faciales codificados fueron la altura de los pómulos, la separación de los ojos o el ancho de la nariz. A partir de ello, lo que pretenden hacer los expertos mediante la sistematización del proceso y los métodos adecuados es predecir los rasgos faciales de nuestros descendientes, ascendientes o fallecidos, e incluso, de especies humanas casi extinguidas. También podrían ser verdaderos instrumentos útiles de trabajo en antropología y en medicina forense. FULLWILEY apuntó que el sistema se había desarrollado analizando el ADN y las caras de las personas con ascendencia de África occidental y Europa mixta. "Esto lleva a una tecnología que es más capaz de hacer caras que son afroamericanas". FULLWILEY es profesora de Antropología de la Universidad de Stanford (EEUU).

${ }^{7}$ Para elaborar estos análisis los científicos buscan variantes genéticas asociadas con rasgos físicos de la misma manera que se buscan los genes que causan una enfermedad. Se conocen muchas variantes genéticas relacionadas con una característica física pero su contribución es muy pequeña. Por ejemplo, se ha visto en estudios con gemelos que la estatura está determinada en un 80 por ciento por la genética, pero hay 700 variantes genéticas relacionadas con la altura de un individuo y explican solo un $15 \%$ de la diferencia entre una persona y otra. Sin embargo, en otros rasgos es más sencillo acertar porque están determinados por un único gen, como sucede con el color de los ojos y el pelo.
} 
IUS ET SCIENTIA (ISSN 2444-8478) 2018, Vol 4 nº 2, pp.63-86

"El fenotipado forense", Susana ÁLVAREZ DE NEYRA KAPPLER, Universidad Autónoma de Madrid, susana.alvarezdeneyra@uam.es

Recibido: 30/10/2018. Aceptado: 01/12/2018

DOI: http://dx.doi.org/10.12795/IESTSCIENTIA.2018.i02.05

fenotipo es cualquier característica o rasgo observable de un organismo, como su morfología, desarrollo, propiedades bioquímicas, fisiología e incluso comportamiento ${ }^{8}$.

Como hemos indicado, este innovador instrumento forense permite, a partir de una muestra de material biológico, crear la imagen del rostro del sospechoso, lo que algunos podrían denominar "retrato robot". La diferencia entre este último y el recreado por la técnica forense es el porcentaje de acierto al utilizar información genética, introduciendo ciertas variables, de manera que los avances de los últimos años pueden llevar la identificación genética forense a un nivel completamente nuevo e inimaginable hace unos años ${ }^{9}$.

No obstante, según apunta LORENTE $^{10}$, si bien todos los rasgos de una persona tienen una base genética, en algunos de ellos la influencia medioambiental es muy importante (tales como el ejercicio, la dieta, procesos habidos durante la gestación...), hasta el punto de que pueden modelar la apariencia física del individuo. Por ello sería erróneo pensar que el conocimiento de la genética nos dará todas las claves en el ámbito forense. Aun así, nadie duda de que el fenotipado molecular se convertirá en una herramienta muy útil, más allá del retrato robot convencional y con una alta fiabilidad. Sin embargo, dado que nuestro <<retrato robot genético>> no puede tener en cuenta todos los factores que han podido incidir en nuestro posterior aspecto físico, no

\footnotetext{
${ }^{8}$ Realmente, un fenotipo no es más que la forma que tiene el ADN de expresarse en las características físicas: un determinado genoma siempre se verá materialmente de una determinada manera, y éste será el fenotipo- el genoma de los ojos verdes lo hará con un fenotipo de este color, el genoma de color marrón con otro, etc. La idea detrás de estas nuevas investigaciones es, justamente, tomar los genomas encontrados en piezas de ADN y compararlos con otros y sus respectivos fenotipos, con el objetivo de encontrar cierta correlación con diferentes rasgos faciales y, por lo tanto, deducir, característica por característica, cómo se verían los posibles culpables. No obstante, los resultados se deducen en forma de estadísticas, y no hay una fiabilidad del $100 \%$. Sin embargo, los avances en esta materia son imparables.

${ }^{9}$ Otros métodos de identificación facial, como el desarrollado por SHRIVER y CLAES, están más cercanos a las matemáticas, pues se realiza la representación facial a partir de complejos métodos matemáticos, basados en una medición tridimensional de las coordenadas de miles de puntos sobre la cara obtenidos a través del material genético, basándose en el género y la herencia étnica de la persona.

Los investigadores no obstante afirmaron que la ascendencia y el análisis de género sólo puede explicar un $23 \%$ de la variación en las caras y que las variantes genéticas no pueden, en la actualidad, aportar mucho detalle. Pero hay que tener en cuenta que la técnica está todavía en fase de desarrollo temprano y desde entonces se han ido añadiendo muchas variantes genéticas para tratar de mejorar la precisión.

${ }^{10}$ José Antonio LORENTE, es director del Laboratorio de Identificación Genética de la Universidad de Granada (España).
} 
IUS ET SCIENTIA (ISSN 2444-8478) 2018, Vol 4 nº 2, pp.63-86

"El fenotipado forense", Susana ÁLVAREZ DE NEYRA KAPPLER, Universidad Autónoma de Madrid, susana.alvarezdeneyra@uam.es

Recibido: 30/10/2018. Aceptado: 01/12/2018

DOI: http://dx.doi.org/10.12795/IESTSCIENTIA.2018.i02.05

debemos desdeñar por ello al testigo ocular u otros medios tradicionales de determinar la identidad del sospechoso.

Como todo sistema de identificación, en la actualidad el "fenotipado molecular" pasa por una época de asimilación. Su empleo se centra principalmente en auxiliar en casos de investigación que hubieren llegado a una<<vía muerta〉>. El problema reside en que, siendo como es tan novedoso, nada se ha regulado al respecto: ni el procedimiento, ni el valor del fenotipado forense, ni su naturaleza, sus requisitos, etc.

\section{II.- EL FENOTIPADO FORENSE ${ }^{11}$ : APROXIMACIÓN}

Las regiones utilizadas en identificación genética son las no sensibles o no codificantes; es decir, aquellas que no proporcionan información sensible del individuo. Así lo establece expresamente el art. 4 de la LO 10/2007, reguladora de las bases de datos policiales $^{12}$, que circunscribe la identificación genética a la utilización de este ADN llamado <<basura〉> (del inglés, DNA junk).Las regiones no codificantes, si bien unidas funcionan como un código de barras de una persona, por sí solas no ofrecen información de cómo es o de cómo se comporta el individuo. Pero el ADN de esas muestras también cuenta con otras regiones codificantes, llenas de información. Y es ahí donde la genética forense tiene su mayor campo de extensión; la <<última revolución〉> de los laboratorios forenses: el fenotipado forense. Básicamente, y como ya hemos tenido ocasión de apuntar, lo que pretende esta técnica es predecir el aspecto humano a partir de una muestra de ADN hallada en la escena del delito a fines de investigación criminal. La ciencia ha avanzado lo suficiente como para que los forenses puedan

\footnotetext{
${ }^{11}$ FDP, Forensic DNA Phenotyping.

${ }^{12}$ De especial importancia son las bases de datos de ADN con fines de investigación criminal, en las que los perfiles de ADN anónimos obtenidos de vestigios biológicos de la escena del delito pueden ser comparados de forma sistemática entre sí, así como con los obtenidos de individuos que son sospechosos o condenados en una causa penal, ofreciendo una herramienta muy eficaz de identificación humana con una alta potencialidad para reducir el índice de criminalidad de determinados delitos sin autor conocido y, especialmente, aquellos en los que existe una alta reincidencia. ALONSO ALONSO, A., ADN forense, investigación criminal y búsqueda de desaparecidos. DOI: http://dx.doi.org/10.18567/sebbmdiv_RPC.2011.12.1. Artículo publicado en diciembre de 2011.
} 
IUS ET SCIENTIA (ISSN 2444-8478) 2018, Vol 4 nº 2, pp.63-86

"El fenotipado forense", Susana ÁLVAREZ DE NEYRA KAPPLER, Universidad Autónoma de Madrid, susana.alvarezdeneyra@uam.es

Recibido: 30/10/2018. Aceptado: 01/12/2018

DOI: http://dx.doi.org/10.12795/IESTSCIENTIA.2018.i02.05

elaborar un retrato robot aproximado de una persona a partir de una pequeña muestra de ADN.

Diferentes grupos de investigación de Estados Unidos y Europa están desarrollando estos sistemas de análisis para predecir las características físicas de un sospechoso a partir de una pequeña muestra de su material biológico. Es decir, establecer un retrato genético en el que se puede averiguar cuál es su sexo, de qué color tiene los ojos y la piel, su origen étnico, la edad o si su cabello es rizado o liso. Son la última herramienta en la lucha contra el crimen. Esta técnica sería de especial utilidad cuando no hay testigos oculares, ni imágenes ni grabaciones, pero se encuentran restos de ADN, que, una vez comparados con los almacenados en un banco de datos genético, donde se guarda la información de sospechosos o autores de otros casos, no salta un perfil coincidente o, saltando un match, se desconoce al "propietario" de la muestra de ADN.

La ventaja es que se puede estrechar el círculo sobre los sospechosos elaborando un retrato robot que, a diferencia del tradicional, no se construye sobre los recuerdos de un testigo y la interpretación de un dibujante, sino con la ayuda de un programa informático y la precisión de la genética.

\section{III.- DEL ADN FORENSE AL FENOTIPADO FORENSE COMO HERRAMIENTAS EN LA INVESTIGACIÓN DE LOS DELITOS}

Hasta ahora, si se encontraba ADN en el escenario de un crimen, solo podía saberse a quien correspondía si su portador estaba fichado (sistema <<uno contra todos $>>)$. También cuando un individuo sospechoso era identificado, podía compararse su ADN con el encontrado en la escena del crimen (sistema <<uno contra uno >). De este modo, si los perfiles genéticos del sospechoso y la muestra encontrada en la escena coincidían, se deducía que se podía tratar de la misma persona. Lo mismo pasaba con las huellas dactilares. Sin embargo, en un delito en el que no hay testigos ni sospechosos y ninguna cámara de seguridad ha podido captar a nadie, de poco sirve una muestra de ADN del escenario si no salta un match en el cotejo. 
No obstante, sabemos que el ADN contiene nuestro código genético único; es el "plano" del que se construyen nuestros cuerpos. Esto incluye las $<<$ instrucciones genéticas $>$ para nuestro color del pelo, color de ojos ${ }^{13}$, de la piel, forma de la cara, nariz, barbilla... ${ }^{14}$. El fenotipado genético es el proceso de predecir la apariencia física de una persona basándose en su código genético, a partir de muestras dubitadas de donantes desconocidos. En contraposición al método de análisis genético empleado hasta ahora, el fenotipado o retrato molecular no trata de comparar sino de <<predecir>>, y, a diferencia del retrato robot tradicional, el obtenido a partir del fenotipado no dependerá ni de los recuerdos de un testigo ni de la interpretación de un dibujante, sino de un programa informático. No es una ciencia exacta -y es probable que nunca revele una imagen perfecta-, pero se acerca, al menos, lo suficiente, como para ayudar a la policía a resolver ciertos casos. Incluso podría llegar a constituir uno de los primeros pasos en una investigación para restringir el campo de sospechosos a sólo aquellos que coincidan con el fenotipo compuesto. En el ámbito forense ya se ha utilizado para ayudar a las autoridades en la investigación de casos, como veremos más adelante.

\footnotetext{
${ }^{13}$ Quizás donde la ciencia más ha avanzado es respecto de los ojos. Los científicos afirman que el color del iris posee más dimensiones y variaciones que las ya conocidas azul, verde y castaño. Los resultados se han publicado en la revista PLoS (Public Library of Science) Genetics. Los investigadores descubrieron tres nuevos loci genéticos (las posiciones de las secuencias genéticas en cromosomas) que influyen de forma importante en las variaciones naturales y sutiles del color de los ojos que distinguen a una persona de otra, y supone la mayor precisión lograda hasta la fecha en predicción genómica de rasgos cuantitativos complejos humanos y tiene relevancia para futuras aplicaciones forenses. Este nuevo método se utilizó para medir valores de tono y saturación del iris a partir de fotografías digitales en alta resolución de ojos completos. El método resultó tan efectivo que los investigadores recomiendan el fenotipado de precisión (fine phenotyping) como una estrategia útil a la hora de hallar genes relacionados con rasgos humanos complejos, y subrayan que el método es extremadamente rentable, portátil y de gran eficiencia. El Dr. Manfred KAYSER, investigador del Departamento de Biología Molecular Forense del Centro Médico Universitario Erasmo, subrayó el destacado potencial de los resultados de la investigación para facilitar investigaciones forenses y policiales. KAYSER ayudó a desarrollar la tecnología de HIrisPlex usada para predecir color del ojo, y es también uno de los más activos defensores del uso de esta técnica. El HIrisPlex analiza 24 variantes genéticas, con aproximadamente un 75\% de precisión para el color del cabello. A finales de 2015 publicó un artículo en la revista ForensicScience International: Genetics, en el que explicaba las bases metodológicas del FDP (Forensic DNA Phenotyping). En dicho artículo abordaba sus potenciales usos y también examinaba algunas consideraciones éticas de su aplicación en el contexto judicial.

Como curiosidad diremos que no sólo los científicos están llevando los estudios de ADN a un nivel superior: el Dr. DEWEY-HAGBORG, profesor asistente de estudios de arte y tecnología en el Instituto de Arte de Chicago, incluso hizo una exposición artística donde combinó la impresión 3D y el fenotipado para generar las caras de extraños, basándose en muestras de ADN abandonado.

${ }^{14}$ Con la tecnología actual el fenotipado de ADN puede revelar etnicidad, género, color de ojos, color del pelo, altura e incluso edad, aunque la precisión actual no es del 100\%. Puede también ser utilizado para proyectar una forma general de la cara y se está avanzando para identificar la calvicie, textura del pelo (rizado o liso), que pueda acercarse lo máximo posible al retrato del presunto autor.
} 


\section{IV.- NATURALEZA}

Aunque al fenotipado forense se le conoce como el <<testigo forense $>>$ es evidente que no se corresponde con una prueba testifical. No comparte las características básicas que definen estos medios de prueba. Los testigos son las personas físicas, distintas de las partes, que deben declarar sobre sus percepciones o deducciones de hechos pasados.

El testigo es, por definición <<clásica〉>, una persona física, ajena al proceso, citada por el órgano jurisdiccional (o en la fase de instrucción por el director de la investigación), a fin de que preste declaración de ciencia sobre hechos pasados, relevantes para la averiguación y constancia de la perpetración de los delitos con todas las circunstancias que pueden influir en su calificación, y en la concreción de los delincuentes ${ }^{15}$.

Por el contrario, y por mucho que se quiera asimilar las nuevas técnicas de determinación de los presuntos autores de los hechos como $<<$ testificales $>>{ }^{16}$, lo cierto es que la función del fenotipado forense no es medio de prueba alguno y debería entenderse que se limita a la de ser un paso inicial en la investigación, que, de resultar positiva, a través de una posterior prueba de cotejo de perfiles genéticos, pueda suponer una fuente inmediata de investigación. Entendemos que no puede acceder al juicio oral. Así lo considera Ángel CARRACEDO ${ }^{17}$, al afirmar que «la predicción de características físicas a partir de $\mathrm{ADN}$, será una herramienta que no se utilizará como prueba judicial, sino como una ayuda para la policía para orientar sus investigaciones».

\footnotetext{
${ }^{15}$ Vid., art. 701 y siguientes de la Ley de Enjuiciamiento Criminal.

${ }^{16}$ Como no lo es tampoco una filmación o una grabación de imágenes.

${ }^{17}$ Ángel CARRACEDO es catedrático de Medicina Legal en la Universidad de Santiago y director de su Instituto de Ciencias Forenses. En su centro, por ejemplo, se ha realizado la búsqueda y el análisis de marcadores epigenéticos para determinar la edad y el patrón de calvicie de una persona. Los sistemas de análisis utilizados les permiten conocer estas características físicas, aunque las muestras sean pequeñas y estén degradadas.
} 
IUS ET SCIENTIA (ISSN 2444-8478) 2018, Vol 4 nº 2, pp.63-86

"El fenotipado forense", Susana ÁLVAREZ DE NEYRA KAPPLER, Universidad Autónoma de Madrid, susana.alvarezdeneyra@uam.es

Recibido: 30/10/2018. Aceptado: 01/12/2018

DOI: http://dx.doi.org/10.12795/IESTSCIENTIA.2018.i02.05

Debemos tener claro que la funcionalidad de esta pericia se manifiesta de una doble manera: se puede extraer información de un resto de ADN, que nos dirija la investigación hacia, p.ej., personas de determinada etnia, o bien podemos dar un paso más allá, y configurar el retrato robot de esa persona. Mientras la primera opción es científicamente más fiable, no así la segunda, que resulta ser mucho más genérica, como veremos en lo que hemos denominado el <<Experimento social $>>$ del fenotipado forense.

El argumento de KAYSER, uno de los principales impulsores y defensores de esta técnica, para recomendar el uso del fenotipado forense está basado en una analogía. Para él, los resultados que arroja el fenotipado por ADN pueden servir como testigo biológico, de manera similar a cómo funcionan los testigos oculares. La analogía parece evidente; incluso el aura de cientificidad que envuelve al fenotipado parecería ponerlo en ventaja frente al testimonio de un testigo ocular, el cual "se sabe", dice KAYSER, que es "poco fiable". Si en el caso de la observación directa (testigo ocular) se obtiene un retrato hablado que se incluye en las investigaciones, la imagen obtenida a través de Snapshot ${ }^{\mathrm{TM}}$ (testigo biológico) puede considerarse también como un retrato hablado y estar sometido al mismo tipo de consideraciones legales. Pero se trata de una falsa analogía. La falacia consiste en comparar ambos hechos, la observación directa y el fenotipado por ADN, poniendo de relieve las semejanzas entre ellos mientras se dejan de lado diferencias importantes que hacen la comparación incorrecta desde el punto de vista lógico.

Por ello, el argumento de KAYSER es falaz, porque, como hemos apuntado, del hecho de que el fenotipado forense arroje una imagen, no se concluye que ésta y el retrato hablado de un testigo ocular compartan las mismas propiedades ni que sean similares en todos los aspectos (el proceso inferencial es muy distinto). Además, persiste el problema de su validez como prueba. Mientras que el testimonio de los testigos oculares está admitido (reconociendo sus sesgos e imprecisiones) como medio de prueba en el juicio oral, aún no se ha determinado si el fenotipado puede contribuir de manera relevante y consistente en la investigación criminal. 
IUS ET SCIENTIA (ISSN 2444-8478) 2018, Vol 4 nº 2, pp.63-86

"El fenotipado forense", Susana ÁLVAREZ DE NEYRA KAPPLER, Universidad Autónoma de Madrid, susana.alvarezdeneyra@uam.es

Recibido: 30/10/2018. Aceptado: 01/12/2018

DOI: http://dx.doi.org/10.12795/IESTSCIENTIA.2018.i02.05

Sobre la base de los estudios del software desarrollado por SHRIVER, que sirve para realizar una imagen en cuestión de minutos a partir de restos genéticos, se hizo una prueba en el diario The New York Times, dirigida por Andrew POLLACK ${ }^{18}$, para comprobar la utilidad y precisión de este método. La cuestión era si sería posible identificar a los propios colegas del diario The New York Times basándose en dichos estudios, explicando previamente que las representaciones o retratos robots no estaban ajustados en cuanto a la edad. John Markoff, reportero de 65 años, y Catherine Spangler, de 31 años, cámara, se ofrecieron a compartir su perfil genético ${ }^{19}$, obviándose sus nombres, información sobre su estatura, peso o edad. SHRIVER procesó los datos y envió representaciones de las caras de los donantes. Se distribuyeron las imágenes a los colegas por correo electrónico y un grupo privado de Facebook, y les preguntaron si podían identificar a estos individuos. Se les advirtió que debido a que la edad y el peso no podían determinarse a partir del ADN, la persona podría ser mayor o más joven, más gruesa o más delgada que la imagen sugerida. Respecto de John Markoff, doce personas respondieron inmediatamente que no podían adivinar la persona, porque las imágenes eran demasiado genéricas. De los cincuenta participantes restantes, ninguno identificó al $<<$ donante〉>. El hombre que recibió más votos fue Andrew Ross Sorkin, columnista de negocios y editor de Dealbook. También se sugirieron otras posibilidades, en su mayoría hombres blancos, pero ninguno identificó al verdadero donante. Cuando llegó el retrato del ADN de Catherine Spangler, diez personas de sesenta y dos participantes, la identificaron correctamente. Aun así, los participantes pusieron los nombres de otras diez mujeres distintas. Alrededor de la mitad de ellas eran de ascendencia europea, la

\footnotetext{
${ }^{18}$ Periodista de The New York Times.

${ }^{19} \mathrm{Un}$ «perfil genético» no es más que un patrón de fragmentos cortos de ADN ordenados de acuerdo a su tamaño que son característicos de cada individuo. Dicho patrón es fácilmente convertible en un sencillo código numérico muy fácil de almacenar y comparar con un alto poder de discriminación. La mayoría de los perfiles de ADN que se obtienen en los laboratorios forenses se basan en el estudio simultáneo de un conjunto de 10 a 17 regiones cortas del ADN nuclear, denominadas Short Tandem Repeats (STRs), que están distribuidas en los distintos cromosomas humanos y que presentan una alta variabilidad de tamaño entre los distintos individuos. Se trata de pequeñas regiones de 100-500 nucleótidos compuestas por una unidad de 4-5 nucleótidos que se repite en tandem " $n$ " veces. El número de veces que se repite esta unidad de secuencia presenta una gran variabilidad entre los individuos de una población. Como estos perfiles tienen una procedencia compartida al $50 \%$ por el padre y la madre, se pueden utilizar también en la investigación biológica de la paternidad. ALONSO ALONSO, Antonio. ADN forense, investigación criminal y búsqueda de desaparecidos.DOI: http://dx.doi.org/10.18567/sebbmdiv_RPC.2011.12.1. Artículo publicado en diciembre de 2011.
} 
IUS ET SCIENTIA (ISSN 2444-8478) 2018, Vol 4 nº 2, pp.63-86

"El fenotipado forense", Susana ÁLVAREZ DE NEYRA KAPPLER, Universidad Autónoma de Madrid, susana.alvarezdeneyra@uam.es

Recibido: 30/10/2018. Aceptado: 01/12/2018

DOI: http://dx.doi.org/10.12795/IESTSCIENTIA.2018.i02.05

otra mitad, de ascendencia asiática. Curiosamente, la ascendencia de Catherine Spangler es mitad coreana y mitad de Europa del norte ${ }^{20}$.

Para construir su modelo, SHRIVER midió 7.000 coordenadas dimensionales en la cara y analizó sus vínculos con miles de variantes genéticas. Aunque el sexo y la mezcla ancestral ${ }^{21}$ no son el único predictor de la forma de cara en este modelo, sí son los principales influyentes ${ }^{22}$.

\section{VI.- CASOS EN QUE SE HA APLICADO PARA LA RESOLUCIÓN DE DELITOS}

Gracias a los análisis del Instituto de Medicina Legal de la Universidad de Santiago $^{23}$ de Compostela (USC), se pudo resolver en el año 2009 un complicado caso en Londres de violaciones en serie y agresiones sexuales a un centenar de hombres y mujeres de edad avanzada (entre 63 y 100 años). Scotland Yard, la policía metropolitana de Londres, bautizó el caso con el nombre de "operación Minstead". Tenían el ADN del presunto autor de los hechos y sabían que todas esas agresiones habían sido perpetradas por el mismo autor. Sin embargo, su rostro era una incógnita. La policía tomó, analizó y comparó 21.500 muestras de ADN, aunque ninguna coincidió con el perfil genético del atacante.Tras20 años de investigaciones, finalmente la policía logró resolver los delitos gracias a los expertos en Genética Forense de la USC, que determinaron el fenotipado

\footnotetext{
${ }^{20}$ Según SHRIVER, "las personas con los mismos niveles de ascendencia pueden tener un aspecto diferente".

${ }^{21} \ll$ En el caso de la ancestralidad no solo queremos llegar a decir si un individuo es norteafricano o europeo, sino ser más exactos aún e identificar, por ejemplo, si tiene ancestros suecos o españoles. Pero el gran objetivo es desarrollar una herramienta bioinformática que integre todos los parámetros y que nos dé una probabilidad sobre el aspecto físico del individuo», subraya CARRACEDO. La Voz de Galicia. 1 de junio de 2017.

${ }^{22}$ Algo que ha suscitado preocupación sobre el potencial para el perfil racial.

${ }^{23}$ El Instituto de Ciencias Forenses de la Universidad de Santiago participa, junto con otros centros universitarios, grupos policiales e instituciones de Justicia de ocho países, en el proyecto europeo Visage, financiado con cinco millones de euros con cargo al programa H2020. El objetivo es determinar las características físicas de los supuestos delincuentes, como el color de los ojos, de la piel, del pelo, incluso si es rizado, liso o canoso, la altura, la edad y su ancestralidad, o, lo que es lo mismo, su origen geográfico. No obstante, debemos pensar que no sólo la determinación de ciertas características del sospechoso puede tener relevancia, sino que la exclusión puede ser aún más importante. Afirma al respecto Susan WALSH, profesora adjunta de biología en la Universidad de Indiana/Purdue University Indianapolis, que "eso, al menos, reduce a los sospechosos".
} 
IUS ET SCIENTIA (ISSN 2444-8478) 2018, Vol 4 nº 2, pp.63-86

"El fenotipado forense", Susana ÁLVAREZ DE NEYRA KAPPLER, Universidad Autónoma de Madrid, susana.alvarezdeneyra@uam.es

Recibido: 30/10/2018. Aceptado: 01/12/2018

DOI: http://dx.doi.org/10.12795/IESTSCIENTIA.2018.i02.05

del ADN del violador ${ }^{24}$ y su origen geográfico (caribeño). Una vez obtenida su imagen, no fue muy difícil dar con su identidad. DelroyGrant, el autor de los hechos, fue detenido en el año 2009 y condenado por tales delitos.

Fuera de nuestros laboratorios, también se ha utilizado esta técnica en múltiples ocasiones, y expondremos a continuación sólo algunos de estos casos a modo de ejemplo.

El 9 de enero de 2015 se cumplía el cuarto aniversario de los asesinatos de Candra Alston y de su hija de tres años de edad, Malasia Boykin. No hubo testigos oculares del crimen; las cámaras de seguridad no facilitaron ninguna pista y el ADN del sospechoso no pudo ser cotejado en la base de datos. La investigación estaba en un punto muerto $^{25}$ y la imagen del fenotipo era todo lo que podían seguir. La policía de Columbia (Carolina del Sur), emitió un comunicado de prensa conteniendo lo que se cree que es la primera imagen compuesta en la historia forense realizado enteramente sobre la base de una muestra de ADN. Empezó a mostrar a los vecinos una imagen de un posible sospechoso, de origen afroamericano. El dibujo, como sabemos, no era una recreación artística, sino un rostro generado por ordenador a partir de una muestra de ADN hallada hace cuatro años en la escena del crimen. Sin embargo, el caso continúa sin resolverse.

A finales de los años 90 y hasta los comienzos de la década del 2000, se cometieron una serie de asesinatos en Louisiana. Las declaraciones de testigos oculares y el perfil recreado por del FBI indicaban que el agresor era probablemente un varón caucásico. Después de que los investigadores cotejaran muestras del ADN de millares de varones caucásicos sin encontrar ninguna coincidencia con los restos genéticos hallados en las escenas de los delitos, se realizó una prueba de fenotipado forense. Curiosamente, esta prueba indicó que la ascendencia del sospechoso era 85\% africano-

\footnotetext{
${ }^{24} \mathrm{La}$ técnica ya se estrenó en el atentado del $11 \mathrm{M}$ en Madrid. El análisis de restos de una mochila determinó que el que la llevaba era un español, pero las otras prendas examinadas apuntaban a norteafricanos. La teoría oficial empezaba a desmoronarse.

${ }^{25}$ Creer que las muestras de ADN dubitadas pueden condenar a los culpables y despejar a los inocentes, es desconocer la realidad. Para facilitar la determinación del posible agresor, el ADN tiene que coincidir con otra muestra genética indubitada. Cuando no lo hace, la investigación muchas veces queda paralizada. En el caso de Carolina del Sur, la policía reunió 150 muestras de ADN y realizó 200 entrevistas con probables sospechosos, pero fue en vano.
} 
IUS ET SCIENTIA (ISSN 2444-8478) 2018, Vol 4 nº 2, pp.63-86

"El fenotipado forense", Susana ÁLVAREZ DE NEYRA KAPPLER, Universidad Autónoma de Madrid, susana.alvarezdeneyra@uam.es

Recibido: 30/10/2018. Aceptado: 01/12/2018

DOI: http://dx.doi.org/10.12795/IESTSCIENTIA.2018.i02.05

subsahariano y el $15 \%$ caucásico, señalando a un individuo afroamericano y cambiando la dirección de la investigación. En dos meses, la policía detuvo al autor de los hechos, DerrickTodd Lee, quien fue condenado más tarde por dos de esos asesinatos.

Un asunto de cierta relevancia social fue cuando el 30 de junio de 2015, la cadena de televisión norteamericana NBC en su programa nocturno de noticias, presentó el fenotipado forense de un sospechoso del asesinato en 1988 de April Tinsley, cerca de Fort Wayne, Indiana. La televisión también incluyó una imagen fenotipada de la corresponsal de noticias nacionales Kate Snow, que se realizó con una muestra de saliva obtenida de una botella de agua ${ }^{26}$, para demostrar públicamente la eficacia de este tipo de retrato forense. No obstante, quedó como una anécdota, pues el asunto siguió en vía muerta.

Otro nuevo caso fue el del asesinato de Sierra Bouzigard en Moss Bluff, Louisiana, en el año 2009. La investigación se había centrado en un grupo de varones hispanos con quienes Bouzigard fue visto por última vez. Sin embargo, el fenotipado forense obtenido de las muestras de ADN realizado en el año 2015, indicaba que el sospechoso era predominantemente europeo, con piel clara, y ojos posiblemente azules o verdes y cabello castaño o negro, lo que cambió completamente el rumbo de la investigación.

La policía en Tacoma, Washington, divulgó públicamente el 6 de abril 2016 la instantánea realizada por Parabon de dos sospechosos de las muertes de Michella Welch (de 12 años) y de Jennifer Bastian (13 años), ambas secuestradas en 1986 en el extremo del norte de Tacoma, con tan sólo cuatro meses de diferencia entre ambos secuestros. Los investigadores creyeron durante mucho tiempo que una sola persona había cometido ambos crímenes debido a las semejanzas delictivas entre ambos. Sin embargo, las pruebas genéticas y de fenotipado demostraron que se trataba de dos individuos distintos. Las descripciones realizadas a partir del fenotipado forense se divulgaron para lograr la ayuda de la ciudadanía en la resolución de los casos.

También ha utilizado esta técnica la policía canadiense de la ciudad de Windsor, quien el 21 de abril de 2016 publicaba una foto compuesta del presunto autor del

\footnotetext{
${ }^{26}$ La cadena televisiva había sometido a Parabon para una prueba ciega del fenotipado genético.
} 
IUS ET SCIENTIA (ISSN 2444-8478) 2018, Vol 4 nº 2, pp.63-86

"El fenotipado forense", Susana ÁLVAREZ DE NEYRA KAPPLER, Universidad Autónoma de Madrid, susana.alvarezdeneyra@uam.es

Recibido: 30/10/2018. Aceptado: 01/12/2018

DOI: http://dx.doi.org/10.12795/IESTSCIENTIA.2018.i02.05

secuestro y asesinato de Ljubica Topic, de seis años de edad, en 1971. Se trataba de la primera ocasión en que se utilizaba el fenotipado forense y la divulgación de una imagen en Canadá y, en ese entonces, el caso más antiguo en el que esta nueva tecnología se había aplicado ${ }^{27}$. Desde entonces, la policía de Toronto ha ordenado el fenotipado en 29 muestras para ayudarles a resolver los casos abiertos desde los años 1980 a $2014^{28}$.

Como vemos, el fenotipado forense podría ser de aplicación en casos no resueltos cuya investigación se encuentra en punto muerto. Sin embargo, y hasta la fecha, rara vez ha sido de utilidad como retrato robot, quizás porque las imágenes que muestra son demasiado ambiguas. Por el contrario, sí ha servido para estrechar la investigación sobre etnias de procedencia del presunto autor, e incluso para dar con él gracias a coincidencias parciales por estirpes familiares, como veremos en el siguiente epígrafe.

\section{VII.- EL CASO DE EVA BLANCO}

En España el vacío legal sobre el fenotipado forense ha sido aprovechado para la investigación y resolución del caso de la violación y asesinato de Eva Blanco en el año 1997 en Algete (Madrid). Para ayudar en la investigación de este caso, el alcalde de la localidad había promulgado un bando por el que solicitaba la colaboración de los jóvenes para someterse voluntariamente a un análisis de ADN. El Juez instructor inadmitió dicha prueba. No obstante, desde su asesinato, se conservaba el semen encontrado en el cuerpo de Eva B., a la espera de que, más pronto o más tarde, se obtuviera una muestra de cotejo. La investigación estaba en punto muerto hasta que, en el año 2016, el Instituto de Ciencias Forenses de la Facultad de Medicina de la Universidad de Santiago de Compostela y el Servicio de Criminalística de la Guardia Civil, realizaron un análisis de fenotipado forense que determinó que el ADN del

\footnotetext{
${ }^{27}$ Imagen obtenida por Parabonnanolabs (Parabon). Hay varias empresas dedicadas a ofrecer fenotipados, además de ParabonSnapshot, se dedican a esto Identitase Iluminaa.Iluminaa es el mayor fabricante de secuenciadores de ADN. En el caso deLjubica, la persona presunta autora de los hechos tiene las siguientes características: Piel clara o piel muy clara con $89,2 \%$ de probabilidad. Ojos marrones o avellana con $97,0 \%$ de probabilidad. Cabello castaño o negro con $96,6 \%$ de probabilidad. Cero o pocas pecas con $93 \%$ de probabilidad.

${ }^{28} \mathrm{El}$ encargo se delegó a la empresa Identitas. En diez casos, la calidad de la muestra era demasiado pobre para que se pudiera realizar cualquier análisis.
} 
IUS ET SCIENTIA (ISSN 2444-8478) 2018, Vol 4 nº 2, pp.63-86

"El fenotipado forense", Susana ÁLVAREZ DE NEYRA KAPPLER, Universidad Autónoma de Madrid, susana.alvarezdeneyra@uam.es

Recibido: 30/10/2018. Aceptado: 01/12/2018

DOI: http://dx.doi.org/10.12795/IESTSCIENTIA.2018.i02.05

sospechoso correspondía a una persona nacida en el norte de África. De esta manera, los agentes centraron sus pesquisas en buscar sospechosos en Algete que procedieran de esta zona y que hubiesen vivido o viviesen en la zona. Había más de 1.000 sospechosos. Muy pronto llamó la atención de los investigadores el nombre de A. C. G, que había huido de Algete a los dos años del crimen. La Guardia Civil centró sus pesquisas en él y pronto descubrieron que tenía un hermano que vivía aún en Algete. Los agentes consiguieron una muestra de ADN del hermano para descubrir si era similar al ADN del registro genético hallado en el cadáver de Eva Blanco. El laboratorio de criminalística de la Guardia Civil cotejó las muestras y dio por fin a los agentes la noticia que tantos años llevaban esperando. Los restos de ADN hallados en el cuerpo sin vida de Eva Blanco eran casi idénticos a la huella genética del hermano menor ${ }^{29}$.

\section{VIII.- PROBLEMAS DERIVADOS DEL USO DEL FENOTIPADO} FORENSE: BREVE APUNTE

Los problemas derivados del fenotipado forense son muchos y de muy diversa índole. A continuación, mencionaremos algunos de ellos.

Primero, sólo sirve esta herramienta cuando se encuentran restos de ADN en la escena del hecho delictivo, y de tal manera que nos indique o nos pueda hacer creer que pertenecen al presunto autor de aquél.

Segundo, sólo se utilizará cuando, consultada la muestra en la base de datos, no se hubiera hallado un perfil de cotejo indubitado coincidente, de modo que la muestra dubitada sigue siendo tal. Según KAYSER, "cuando en un delito no hay sospechoso no son válidos los métodos tradicionales de análisis de $\mathrm{ADN}$, y describir las características visibles externas del individuo que cometió el delito a través del material hallado en la escena del crimen ayuda a la investigación policial".

Tercero, que lo que vemos a simple vista a veces poco tiene que ver con nuestro código genético y es posible que, a efectos de iniciar una investigación, no siempre

\footnotetext{
${ }^{29}$ El hermano del presunto asesino de Eva Blanco había entregado su muestra de ADN de forma voluntaria a la Guardia Civil y sin quererlo fue el que facilitó su detención. El presunto criminal de la joven de Algete fue delatado por 80 marcadores genéticos que concluyeron el origen biogeográfico y otros 20 pudieron indicar las características físicas del individuo al que pertenecía la cadena de cromosomas.
} 
IUS ET SCIENTIA (ISSN 2444-8478) 2018, Vol 4 nº 2, pp.63-86

"El fenotipado forense", Susana ÁLVAREZ DE NEYRA KAPPLER, Universidad Autónoma de Madrid, susana.alvarezdeneyra@uam.es

Recibido: 30/10/2018. Aceptado: 01/12/2018

DOI: http://dx.doi.org/10.12795/IESTSCIENTIA.2018.i02.05

resulte útil ${ }^{30}$, pues el resultado del fenotipado puede no resultar coincidente con lo expresado por testigos oculares, de modo que se puede dudar de si realmente la muestra biológica hallada pertenece al autor de los hechos o no, dada la discrepancia con la testifical.

Cuarto, en la actualidad, los expertos son escépticos, entendiendo que las caras, que son muy complejas, no siempre pueden ser determinadas a partir del ADN. Mientras que la herencia juega claramente un importante papel -los gemelos idénticos se parecen, obviamente, y la gente se asemeja a sus parientes cercanos-, algunos expertos dicen que, no obstante, poco se sabe todavía sobre la relación entre los genes y las características faciales ${ }^{31}$.

Quinto, el posterior cotejo genético seguirá siendo necesario. Aunque actualmente los rasgos específicos de la pigmentación (piel, ojos, cabello...) son ya previsibles con un índice de probabilidad razonablemente alto, otras características externamente visibles siguen siendo objeto de investigación genética. Hasta que la apariencia individual específica se convierta en exactamente predecible por el fenotipado forense, el perfil de ADN convencional necesita ser realizado subsecuentemente.

Sexto, la inferencia de las características externas visibles de una persona puede suponer una posible colisión con el derecho a la intimidad y a la confidencialidad de sus datos personales. Según KAYSER, el color de ojos, el color de cabello y el color de piel de una persona son visibles a todos, por lo tanto, no puede considerarse información confidencial. Pero la manera en la que el fenotipado forense obtiene esta información no es, por así decirlo, <<a simple vista >> La inferencia que va de la muestra de fluido biológico a la fotografía virtual del potencial sospechoso conlleva una serie de

\footnotetext{
${ }^{30}$ Son innumerables los ejemplos: el pelo se puede teñir o incluso rapar, se puede dejar crecer barba, se puede ganar o perder peso, aparentar mejor o peor salud, consumir sustancias nocivas que incidan negativamente en nuestro aspecto físico; la cara se ha podido desfigurar en un accidente, se ha podido tomar demasiado el sol; nuestra piel puede haberse oscurecido o aclarado, o incluso podemos habernos sometido a algún tipo de cirujía plástica; también hay cambios de género...., en definitiva, puede haber muchos factores que modifiquen sustancialmente nuestro aspecto alejándonos de nuestra herencia genética. Además, hay características no determinadas por la genética, como la edad y el peso. En el caso de la altura, p.ej., si bien los investigadores han encontrado marcadores de altura, nadie ha determinado todavía cómo el ADN puede realmente afectar a lo alto que se puede llegar a ser.

${ }^{31}$ Según Benedikt HALLGRIMSSON, jefe de biología celular y anatomía de la Universidad de Calgary, "es necesario un poco de ciencia ficción en este punto".
} 
IUS ET SCIENTIA (ISSN 2444-8478) 2018, Vol 4 nº 2, pp.63-86

"El fenotipado forense", Susana ÁLVAREZ DE NEYRA KAPPLER, Universidad Autónoma de Madrid, susana.alvarezdeneyra@uam.es

Recibido: 30/10/2018. Aceptado: 01/12/2018

DOI: http://dx.doi.org/10.12795/IESTSCIENTIA.2018.i02.05

presuposiciones (por ejemplo, que hay una correlación entre el origen ancestral de un individuo y la forma de su cara o el color de su piel; que la presencia del material biológico de un individuo en la escena del crimen es un indicador de su participación en el mismo), e implica la generación de un perfil genético y fenotípico y su posterior incorporación a una base de datos para uso forense. El destino que puede dársele a la información así generada, presente o futuro, rebasa las expectativas y las posibilidades de aquello que se observa a simple vista. La apariencia observada y la apariencia inferida no proveen información personal equivalente.

\section{IX.- RECOMENDACIONES .... MIENTRAS EL FUTURO LLEGA}

- Las reconstrucciones faciales basadas en el fenotipado genético no se deben utilizar para cualquier propósito ni anunciarse públicamente como la imagen del presunto autor de un delito, a menos que, y hasta que la técnica esté firmemente probada y admitida por la comunidad científica ${ }^{32}$. Tales reconstrucciones son todavía muy aproximadas y genéricas, y no se puede basar una sospecha ni mucho menos aun, una acusación, sobre la base de una imagen obtenida de esta manera. Podría cuestionarse su posible uso, tanto en sede de instrucción como en el juicio oral, pues estas técnicas carecen de soporte legal.

- El retrato robot obtenido a partir del perfil molecular de los sospechosos puede, no obstante, resultar útil para aquellos casos en los que no es posible compararlo con el ADN registrado en los bancos de datos de la policía, pero también para resolver falsas identificaciones. Ocurre más de lo deseable que los testigos de un suceso, bien porque están nerviosos y tienen miedo, o bien porque los hechos ocurren de noche o con escasa iluminación o visibilidad, ofrecen una identificación que no se corresponde con la realidad, lo que ha llevado a falsas condenas ${ }^{33}$. El fenotipado forense podría reducir los falsos positivos en las tareas de identificación perceptiva.

\footnotetext{
${ }^{32}$ Excedería el propósito de este estudio analizar los criterios Frye o Daubert, para la admisibilidad científica de las nuevas técnicas.

${ }^{33}$ Es lo que ha probado el Proyecto Inocencia en Estados Unidos, que ha permitido exonerar de un crimen mediante pruebas genéticas a centenares de personas que cumplían condena.
} 
IUS ET SCIENTIA (ISSN 2444-8478) 2018, Vol 4 nº 2, pp.63-86

"El fenotipado forense", Susana ÁLVAREZ DE NEYRA KAPPLER, Universidad Autónoma de Madrid, susana.alvarezdeneyra@uam.es

Recibido: 30/10/2018. Aceptado: 01/12/2018

DOI: http://dx.doi.org/10.12795/IESTSCIENTIA.2018.i02.05

- Cuando se deduzca que un sospechoso es una persona de color, también se corre el riesgo de aumentar los prejuicios sociales, incrementando aún más los riesgos para las personas inocentes ${ }^{34}$ e incluso para determinadas etnias.

- La imagen del autor real puede no parecerse a la imagen especulativa, que podría terminar desviando o perjudicando de alguna manera la investigación, máxime si se contradice con las declaraciones de los testigos oculares.

- Existe también el peligro de que algunos miembros de la policía (los menos escépticos o prudentes) den credibilidad excesiva a estas reconstrucciones especulativas, intentando usarlas en su totalidad o en parte para dirigir sus investigaciones contra una determinada persona.

- Conviene establecer en qué fase del proceso se puede recurrir a estas técnicas; en qué casos y con qué requisitos. Y, lo que es de mayor importancia, qué valor y credibilidad se le puede dar al fenotipado forense. Consideramos que, a pesar de la grandilocuencia con que se ha definido a esta técnica como el <<nuevo testigo forense >>, aun nos movemos en el campo de la especulación y tan sólo debería utilizarse como un instrumento que ayude al inicio de la investigación en la determinación del presunto autor de los hechos, y sin que los resultados del fenotipado forense puedan alcanzar al juicio oral.

- Es evidente que en algunas circunstancias puede tener sentido utilizar el fenotipado genético en una investigación, pero sólo cuando el vínculo entre los genes y las características externas se base en una ciencia demostrada, revisada por pares y ampliamente aceptada por la comunidad científica, tal como es aparentemente ahora el caso del cabello y del color de los ojos. Sin duda, puede ser útil reducir el posible número de sospechosos, pero no siendo el fenotipado lo suficientemente específico a día de hoy, no debe ser utilizado para <<crear >> sospechosos cuando no se tiene ninguno.

- Tampoco se debe usar para presionar a las personas para que "voluntariamente" proporcionen muestras de ADN o para someterse a cualquier otra técnica intrusiva de investigación. Hay que evitar una cierta euforia que anime a la

\footnotetext{
${ }^{34}$ Así, en opinión de FULLWILEY, profesora de Antropología en Stanford.
} 
IUS ET SCIENTIA (ISSN 2444-8478) 2018, Vol 4 n² 2, pp.63-86

"El fenotipado forense", Susana ÁLVAREZ DE NEYRA KAPPLER, Universidad Autónoma de Madrid, susana.alvarezdeneyra@uam.es

Recibido: 30/10/2018. Aceptado: 01/12/2018

DOI: http://dx.doi.org/10.12795/IESTSCIENTIA.2018.i02.05

policía a buscar entre la población a aquellos que cumplan con las características físicas de ese retrato robot que ofrece el fenotipado genético ${ }^{35}$.

\section{X.- CONCLUSIONES}

Nadie cuestiona que los avances científicos van por delante de la regulación jurídica. Ello nos obliga a los juristas a hacer un continuo trabajo de adaptación legislativa, para dar cobertura legal a las intromisiones de las nuevas tecnologías en la esfera de los derechos de los ciudadanos. Esta herramienta genética marca un uso forense sustancialmente diferente del análisis genético de muestras de ADN que sí puede llegar a tener valor como prueba de alta fiablidad en el juicio oral.

Como hemos expuesto, el fenotipado genético se refiere a la predicción de rasgos de apariencia de los donantes de muestras desconocidos (dubitadas), o personas fallecidas desconocidas (desaparecidas), directamente de materiales biológicos encontrados en la escena del hecho delictivo. Es un intento de determinar rasgos físicos del material genético dejado en la escena cuando no se encuentra ninguna coincidencia de la manera convencional. Se le ha denominado -incorrectamente- el testigo biológico. Es posible que los resultados del fenotipado forense pueden proporcionar pistas de investigación para identificar a personas desconocidas, no identificables por marcadores genéticos al no saltar una coincidencia o match con los perfiles almacenados en la base de datos. Los científicos buscan variantes genéticas asociadas con rasgos físicos de la misma manera en que buscan genes que puedan causar enfermedad: estudiando los genomas de personas y buscando correlaciones.

Es cierto que el fenotipado ha sido útil para resolver algunos casos puntuales, pero todavía tiene muchísimas limitaciones: el aspecto exterior de las personas también está influenciado por el entorno, la edad o tipo de vida. Del mismo modo que el hecho de ser portadores de una mutación genética que ha sido relacionada con una enfermedad determinada no es sinónimo de padecer dicha enfermedad, podemos tener una variante genética que ha sido relacionada con un rasgo físico determinado y no manifestarlo. Dicho de otra forma, existen factores, tanto internos como externos, que activan o

\footnotetext{
${ }^{35}$ Incluso en el caso de una muestra de ADN que revele que un sospechoso tiene albinismo o alguna otra condición genética particular. Ello no debe utilizarse para verter los registros hospitalarios, por ejemplo.
} 
IUS ET SCIENTIA (ISSN 2444-8478) 2018, Vol 4 nº 2, pp.63-86

"El fenotipado forense", Susana ÁLVAREZ DE NEYRA KAPPLER, Universidad Autónoma de Madrid, susana.alvarezdeneyra@uam.es

Recibido: 30/10/2018. Aceptado: 01/12/2018

DOI: http://dx.doi.org/10.12795/IESTSCIENTIA.2018.i02.05

reprimen nuestros genes. Aún así, Ángel CARRACEDO reconoce que el primer paso ya se ha dado: "Los modelos probabilísticos deben ser mejorados y seguramente aparecerán otros estudios con más genes y, como en las enfermedades comunes habría que ver interacción gen-gen y con el ambiente (la epigenética ${ }^{36}$ también jugará un papel). Pero proporciona las bases para que se pueda conseguir".

No obstante, debemos reconocer que el fenotipado supone una importante innovación para la investigación de los delitos, entre otros motivos porque reduce significativamente el número de potenciales sospechosos, que coinciden con las características fenotípicas de la muestra genética.

Como todas las nuevas tecnologías, esta técnica debe someterse a un largo proceso antes de que pueda concluirse que es científicamente correcto y legalmente admisible. En la actualidad muchos científicos sostienen que el fenotipado puede, en el mejor de los casos, proporcionar un esquema general de cómo puede llegar a ser una persona.

Hay que tener en cuenta que el fenotipado no puede dar una imagen completamente exacta de nadie, sino tan sólo puede reproducir la apariencia general más probable, basada en el código genético del sujeto. Tampoco puede hacer referencia a modificaciones en el aspecto físico de los sujetos como el cabello teñido, la nariz rota o cambios dentales; cosas que ciertamente pueden cambiar la apariencia de un sospechoso pero que nunca se reflejarán en su ADN. El fenotipado sigue siendo una ciencia en desarrollo; hay un largo camino por recorrer antes de que se utilice comúnmente.

Son, además, muchos los interrogantes jurídicos que se plantean, tales como determinar qué rasgos se pueden identificar y cuáles estarían fuera de los límites permitidos. ¿Qué ocurriría si se pudiera acreditar científicamente la propensión genética a la violencia de un individuo? Nos encontramos ante un ámbito que puede incidir en el derecho a la intimidad de las personas, pues se utiliza información considerada altamente sensible del individuo ${ }^{37}$.

\footnotetext{
${ }^{36}$ La epigenética hace referencia al estudio de los factores que, sin corresponderse a elementos de la genética clásica, básicamente los genes, juegan un papel muy importante en la genética moderna interaccionando con estos primeros. Estos factores genéticos que son determinados por el ambiente celular en lugar de por la herencia.

${ }^{37}$ Puede revelar una serie de enfermedades, o incluso la probabilidad de padecer cáncer, información legalmente protegida.
} 
IUS ET SCIENTIA (ISSN 2444-8478) 2018, Vol 4 nº 2, pp.63-86

"El fenotipado forense", Susana ÁLVAREZ DE NEYRA KAPPLER, Universidad Autónoma de Madrid, susana.alvarezdeneyra@uam.es

Recibido: 30/10/2018. Aceptado: 01/12/2018

DOI: http://dx.doi.org/10.12795/IESTSCIENTIA.2018.i02.05

En cuanto a su admisibilidad, este método se permite en algunos países, pero está prohibido en algunos otros (como Bélgica y Alemania). Otros, lo restringen parcialmente, como es el caso de Holanda, en el que sólo se permite predecir rasgos que resulten visibles públicamente, como el cabello y el color de los ojos. En EEUU se proscribe la posibilidad de determinar la propensión a ciertas enfermedades, al igual que en nuestro país, en donde la LO 10/2007 limita el uso a fines forenses al ADN no codificante. Pero con estricta relación al fenotipado forense, la mayoría de los países, como es el caso de España, aún no han adoptado una postura al respecto. Es necesario preguntarse en qué medida debe permitirse este método de investigación. Cuestiones como la protección de datos y su derecho a la intimidad, la posible estigmatización y discriminación, o incluso el derecho de las personas a no saber lo que su ADN dice sobre su predisposición a sufrir determinadas enfermedades, y el argumento de la "pendiente resbaladiza" 38 , son cuestiones de trascendencia, y no se debe sobreestimar ni tampoco minimizar su importancia. La doctrina actual y las normativas parecen ¿demasiado? cautelosas. El recurso al fenotipado forense quizás podría permitirse para los rasgos perceptibles externamente, tales como color del pelo o de los ojos, o incluso para ciertos rasgos no-sensibles del comportamiento, como ser zurdo o tener una predisposición para fumar. No se debe permitir, sin embargo, para el análisis de otras muchas predisposiciones, como la de sufrir determinadas enfermedades o para conocer otra información sensible como la predisposición para la homosexualidad o la agresividad. Sería también muy discutible si la categoría media de rasgos relativamente sensibles se podría llegar a permitir, así, por ejemplo, los desórdenes médicos aparentes tempranos, como el albinismo o el alcoholismo del inicio adolescente ${ }^{39}$.

El origen étnico y geográfico son también compatibles con los derechos fundamentales, siempre que se tomen medidas para evitar el riesgo de discriminación. Y es que una de las preocupaciones del uso del fenotipado forense es que arroja descripciones que se corresponden con tipos raciales, lo cual puede contribuir a reforzar la de por sí extendida discriminación racial en ciertos sistemas, como el sistema judicial estadounidense.

Si nos fijamos bien, tanto el entusiasmo como el escepticismo que rodean el uso del fenotipado forense pasan por tomar una posición frente al determinismo genético.

\footnotetext{
${ }^{38}$ En debate o retórica, la pendiente resbaladiza es una de las teorías informales clásicas. Sugiere que una acción iniciará una cadena de eventos que culminarán en un evento posterior predecible, sin establecer o cuantificar las contingencias relevantes. El argumento se conoce también como el efecto dominó.

${ }^{39}$ KOOPS, Bert-Jaap y SCHELLEKENS, Maurice H.M., Forensic DNA Phenotyping: Regulatory Issues. Columbia Science and TechnologyLawReview, Vol. 9, No. 1, 2008.
} 
IUS ET SCIENTIA (ISSN 2444-8478) 2018, Vol 4 nº 2, pp.63-86

"El fenotipado forense", Susana ÁLVAREZ DE NEYRA KAPPLER, Universidad Autónoma de Madrid, susana.alvarezdeneyra@uam.es

Quienes están convencidos de que el ADN posee todas las instrucciones que dan lugar a las características físicas de un individuo, abogan por la utilidad de hacer una especie de ingeniería inversa de la cara a partir de cualquier muestra biológica ${ }^{40}$. Pero los biólogos saben desde hace muchos años que la expresión de los genes es compleja y que el ADN no determina por sí mismo ni la biología ni las características físicas ni conductuales de una persona. Es decir, que no hay una línea causal directa que conecta genes con apariencia. ¿Por qué, entonces, se sigue propagando el modelo determinista y se utiliza como el fundamento teórico de una nueva tecnología forense? Una posible respuesta está en la aparente simpleza del modelo, que permite transitar del determinismo genético al determinismo tecnológico en un solo paso: el desarrollo de una tecnología que identifique a un criminal a partir de una pequeñísima concentración de su ADN, sin necesidad de compararlo con nada, como la solución tecnológica a los problemas de inseguridad y de justicia.

En definitiva, aún es pronto para saber si esta herramienta va a convertirse en la nueva reina de las pruebas forenses, pero parece que quiere convertirse en el principal testigo de los hechos, aunque, a día de hoy, todavía está lejos de lograr ese objetivo. Pero el avance de la ciencia es imparable y los juristas debemos estar preparados para dar la cobertura legal necesaria a esta materia, en protección de los derechos de los individuos que se vean afectados por estas técnicas.

\footnotetext{
${ }^{40}$ Sobre todo si tenemos en cuenta las enormes ganancias que puede reportar, ya que el coste de un perfil compuesto es de alrededor de 5,000 USD.
} 